\title{
A INTERAÇÃO PROJETUAL ENTRE A ERGONOMIA E A EMOÇÃO: UMA PROPOSTA DE DEFINIÇÃO DE REQUISITOS PROJETUAIS PARA O DESIGN DE PRODUTOS A PARTIR DA OPINIÃO DOS USUÁRIOS
}

\author{
THE PROJECT INTERACTION BETWEEN ERGONOMICS AND \\ EMOTION: A PROPOSAL FOR DEFINING PROJECT REQUIREMENTS \\ FOR PRODUCT DESIGNING THE USERS 'OPINION
}

\author{
Suzi Mariño ${ }^{1}$, D.Sc., Carina Silveira ${ }^{2}$, M.Sc., \\ Paulo dos Santos ${ }^{3}$, Ruth Ferreira ${ }^{3}$ \\ (1) Universidade do Estado da Bahia e Universidade Federal da Bahia \\ e-mail: suzimarino@gmail.com \\ (2) Universidade do Estado da Bahia e Universidade Federal da Bahia \\ e-mail: carinassilveira@gmail.com \\ (3) Universidade do Estado da Bahia \\ e-mail: henriqueoupaulo@gmail.com/ruth.designmoda@gmail.com
}

PALAVRAS-CHAVE: Ergonomia; Parâmetros; Bicicletas.

\begin{abstract}
Esta pesquisa tem por objetivo mostrar o estudo comparativo das bicicletas Mountain Bike e de transporte, tendo como base o experimento realizado por MariñoPequini (2005) onde foi avaliado os níveis de dor/desconforto considerando a postura do tronco e o ajuste do selim e assim encontrar a relação do usuário com o produto a fim de definir parâmetros de usabilidade entre ambos. A partir disso, objetiva-se avaliar de acordo com os requisitos estéticos; função estética e nível visceral o comportamento dos usuários na escolha de um produto, enfatizando a importância desses aspectos no design de produtos. Nesse artigo será proposto parâmetros utilizados para elaborar recomendações projetuais no requisito estético/simbólico de um produto.
\end{abstract}

KEY-WORDS: Ergonomics; Parameters; Bicycle.

This research aims to show the comparative study of Mountain Bike and Transport bicycles, based on the experiment carried out by MariñoPequini (2005), where the pain and discomfort levels were evaluated considering the posture of the trunk and the adjustment of the saddle and Thus to find the relation of the user with the product in order to define parameters of usability between both. From this, we aim to evaluate according to the aesthetic requirements; Aesthetic function and visceral level the behavior of users in the choice of a product, emphasizing the importance of these aspects in product design. In this article will be proposed parameters used to elaborate project recommendations on the aesthetic / symbolic requirement of a product. 


\section{$16^{\circ}$ \\ ERGODESIGN USIHC CINAHPA}

$16^{\circ}$ Ergodesign - Congresso Internacional de Ergonomia e Usabilidade de Interfaces Humano Tecnológica: Produto, Informações Ambientes Construídos e Transporte

$16^{\circ}$ USIHC - Congresso Internacional de Ergonomia e Usabilidade de Interfaces Humano Computador

CINAHPA | 2017 - Congresso Internacional de Ambientes Hipermídia para Aprendizagem.

\section{Introdução}

Esta pesquisa propõe estimular o desenvolvimento de projeto de produtos que atendam aos requisitos técnico, ergonômico e estético e as funções prática, estética e simbólica, a partir do experimento realizado por MariñoPequini (2005) onde a autora utilizou a metodologia ergonômica para encontrar a relação do usuário com o produto e assim, definir parâmetros de usabilidade entre ambos.

Ressaltando então a importância de atender também ao requisito estético e as funções estéticas e simbólicas de forma a torná-los mais atraentes atingindo a emoção no nível visceral dos usuários.

Os atuais estudos voltados para o design mostram como é feita a escolha de um objeto pelo usuário. Surgem estudos que mostram que não só os critérios técnico e funcional, mas, na maioria das vezes, as escolhas são feitas com base nas memórias (DAMAZIO, 2013) e a emoção (NORMAN, 2008; DESMET, 2009; TONETTO, 2011) que o objeto traz. No design, a aparência dos objetos está relacionada a seus atributos de configuração física e de identidade visual gerada através da cognição humana interligada às emoções. O valor atribuído a um objeto, seja ele de utensílios ou tecnológicos, está diretamente relacionado à experiência afetiva do usuário. Ou seja, a emoção implica nas escolhas que fazemos e não a qualidade de usabilidade que os produtos oferecem às pessoas.

\footnotetext{
As emoções causadas pelas interações com um produto podem ser influenciadas por fatores como estética, funcionalidade, marca, entre outros, além de serem complexas, pessoais, mutáveis, temporais e culturalmente dependentes. Podemos atender as emoções como reações afetivas que, pela sua intensidade, nos mobilizam para algum tipo de ação. Elas são poderosas manifestações dos nossos instintos e impulsos, resultantes de alterações fisiológicas controladas pelo sistema cerebral, que responde ao conteúdo dos pensamentos relativos a um estímulo recebido. (FONTOURA E ZACAR, 2008, p.30).
}

Desta forma, o trabalho a ser desenvolvido se insere no contexto de pesquisa que tem como propósito validar a hipótese de que os usuários escolhem seus produtos pela aparência em detrimento dos requisitos ergonômico e tecnológico, fazendo um estudo comparativo da aparência das bicicletas mountain bike e de transporte com base na pesquisa desenvolvida por MariñoPequini (2005).

A aparência do objeto, além de reunir o requisito estético e as funções estética e simbólica, atinge o nível visceral, caracterizado por ser um dos três níveis estruturais do cérebro. O nível visceral é o primeiro estágio cognitivo da relação do usuário com o objeto. Através dele julgamos o que é certo ou o que é errado, bom ou ruim, mesmo antes de ter um contato físico com o produto. A emoção se encontra em paralelo com a estética, atratividade e beleza, também está diretamente ligada a aparência, ou seja, ao nível visceral (NORMAN, 2008). Tal fato tem despertado um grande interesse em diversas áreas de conhecimento como a neurociência, psicologia, filosofia, antropologia e sociologia, entre outras.
Uma das maneiras pelas quais as emoções trabalham é por meio de substâncias químicas neuroativas que penetram determinados centros cerebrais e modificam a percepção, o comportamento e os parâmetros de pensamento. (NORMAN, 2008).

Ao projetar com foco na emoção, os designers estarão voltando sua atenção ao usuário e ao modo como interagem e interpretam o meio físico e social. A usabilidade e tecnologia são importantes, mas sem diversão, alegria, entusiasmo, raiva, frustração e prazer nossas vidas seriam incompletas. Sendo assim, pretende-se com o desenvolvimento desta pesquisa propor parâmetros que serão utilizados para elaborar recomendações projetuais no requisito estético/simbólico de um produto a fim de torná-los mais atraentes e competitivos. 


\section{$16^{\circ}$ \\ ERGODESIGN USIHC CINAHPA}

\section{Ergonomia aplicada ao design de bicicletas}

As bicicletas de transporte e mountain bike selecionadas para o estudo comparativo desta pesquisa tiveram como referência o experimento realizado por MariñoPequini(2005), onde a autora avaliou os níveis de dor/desconforto considerando a postura do tronco e o ajuste do selim.

A autora utilizou a metodologia ergonômica para encontrar a relação do usuário com o produto e assim, definir parâmetros de usabilidade entre ambos. Para obtenção dos dados, foram realizadas observações com um grupo de usuários, de forma a levantar o nível de desconforto/dor em relação ao uso da bicicleta de acordo com o tipo de postura assumida. Foram realizadas observações, em seis sessões, de todos os indivíduos da amostra, para registros fotográficos das posturas assumidas e, ao término de cada sessão, aplicados questionários Escala de desconforto/dor (CORLLET,WILSON, 1986 apud MARIÑOPEQUINI, 2005).

Foi utilizada como aparato do experimento a bicicleta ergométrica Monark Ergomedic 828-E (Figuras 1 e 2), a qual teve o selim original substituído por um selim de bicicleta injetado em poliuretano de alta resistência para prática de ciclismo in door, ou tendo o tipo de selim que os ciclistas selecionados para a amostragem utilizam no seu dia-a-dia. A bicicleta foi ajustada de acordo com o biótipo dos usuários, nos tipos tradicional ${ }^{1} \mathrm{e}$ aerodinâmico ${ }^{2}$ (Figuras 3 e 4 ) as quais, nesta pesquisa correspondem respectivamente a bicicleta de transporte e Mountain Bike.

\footnotetext{
${ }^{1}$ Bicicleta do tipo que mantém o usuário com o tronco ereto (Figura 1.1 );

${ }^{2}$ Bicicleta do tipo que mantém o usuário com o tronco em flexão (Figura 1.2);
}

$16^{\circ}$ Ergodesign - Congresso Internacional de Ergonomia e Usabilidade de Interfaces Humano Tecnológica: Produto, Informações Ambientes Construídos e Transporte

$16^{\circ}$ USIHC - Congresso Internacional de Ergonomia e Usabilidade de Interfaces Humano Computador

CINAHPA | 2017 - Congresso Internacional de Ambientes Hipermídia para Aprendizagem.

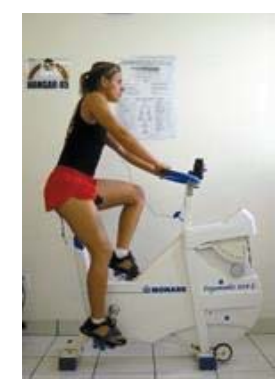

Figura 1 - Bicicleta tradicional -

correspondente à bicicleta de transporte.

Fonte: MariñoPequini (2005)

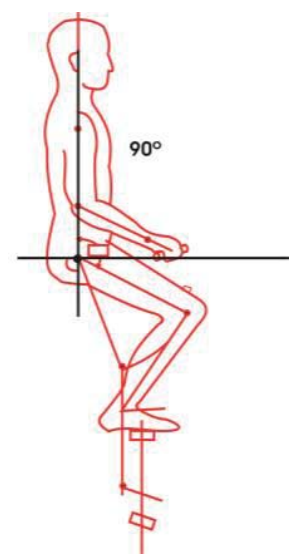

Figura 3 - Postura assumida em bicicleta tradicional - 'transporte'

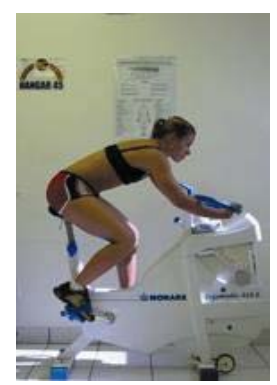

Figura 2 - Bicicleta aerodinâmica correspondente a bicicleta mountain bike.

Fonte: MariñoPequini (2005)

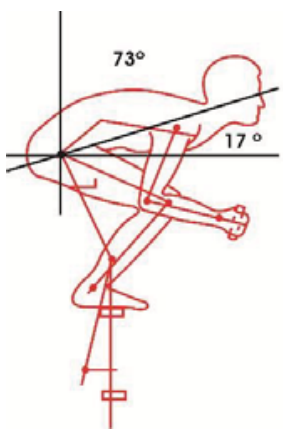

Figura 4 - Postura assumida em bicicleta aerodinâmica - 'mountain bike'

Fonte: Dreyfuss

(1966 apud MARIÑOPEQUINI, 2005).

Para a inclusão da amostra a autora estabeleceu os seguintes critérios:

- Indivíduos saudáveis: com possibilidades físicas de utilizar bicicletas para lazer, transporte ou prática de esporte e que não possuíssem nenhum tipo de doença que os impedisse de praticar atividades físicas conforme recomendações médicas;

- Faixa etária: definida de acordo com o nível de condicionamento físico dos participantes a partir do desempenho da frequência cardíaca, que mostra o nível de condicionamento
Realização:

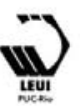




\section{$16^{\circ}$ \\ ERGODESIGN USIHC CINAHPA}

$16^{\circ}$ Ergodesign - Congresso Internacional de Ergonomia e Usabilidade de Interfaces Humano Tecnológica: Produto, Informações Ambientes Construídos e Transporte

$16^{\circ}$ USIHC - Congresso Internacional de Ergonomia e Usabilidade de Interfaces Humano Computador

CINAHPA | 2017 - Congresso Internacional de Ambientes Hipermídia para Aprendizagem. quando se mantém abaixo de $90 \%$ da máxima, mesmo estando exposto a grande esforço;

- Sexo: masculino e feminino;

- Prática de atividade física: mínimo de três vezes por semana (corrida, ciclismo, musculação, ginástica localizada etc.);

- Estatura: do $2,5^{\circ}$ percentil feminino ao $97,5^{\circ}$ percentil masculino, conforme recomendações antropométricas de Diffrient et al. (1981);

- Habitantes da cidade do Salvador.

Foram consideradas três tipos de variáveis:

a) Variáveis Independentes: Tipo da bicicleta (Tradicional - 'transporte' e Aerodinâmica 'montanha'); Altura do selim (correto; $10 \%$ abaixo do correto; e $10 \%$ acima do correto; conforme apresentaremos a seguir).

b) Variável Dependente: Nível de desconforto/dor (Escala de CORLLET e WILSON, 1986:326 apud MARIÑOPEQUINI, 2005).

c) Variáveis controladas: Sexo; Estatura; Alimentação; Postura na bicicleta; Ajustes da bicicleta; Carga da bicicleta; Sequências das sessões; Frequência cardíaca; Intervalo entre as sessões de 30 minutos; Práticas de outras atividades físicas no período do experimento.

Os resultados do experimento mostraram a variação na postura do tronco em duas situações diferentes para que fossem avaliados os níveis de desconforto em 28 regiões do corpo. Para isso, foram medidos os tempos pedalados, a velocidade, a distância percorrida e os batimentos cardíacos, e, ao final de cada sessão, foi solicitado aos participantes que respondessem a escala de avaliação corporal para detectar os níveis de desconforto/dor nas várias regiões do corpo e, de posse destes resultados, indicar qual o tipo de bicicleta mais confortável do ponto de vista postural, se a postura tradicional - 'transporte' com o tronco ereto, ou se a postura aerodinâmica 'mountain bike' - com o tronco flexionado; e, do ponto de vista dimensional no que diz respeito à altura do selim.
A amostra da população selecionada partindo de alguns critérios citados anteriormente foi de homens com faixa etária média de 30 anos, peso médio $77 \mathrm{~kg}$ e estatura média de $179,7 \mathrm{~cm}$, e mulheres com faixa etária média de 33 anos, peso médio $57 \mathrm{~kg}$ e estatura média de $162,7 \mathrm{~cm}$. Além disso, todos os indivíduos, de ambos os sexos, tinham excelente condicionamento físico e eram praticantes de ciclismo. Foram selecionadas 20 pessoas (10 homens e 10 mulheres) para pedalar cada tipo de bicicleta durante meia hora, avaliando assim o nível de dor/desconforto destes em relação as 28 partes do corpo: 00 pescoço, 01 cervical, 02 dorsal, 03 cintura, 04 lombar, 05 região púbica, 06 ombro esquerdo, 07 ombro direito, 08 braço esquerdo, 09 braço direito, 10 cotovelo esquerdo, 11 cotovelo direito, 12 antebraço esquerdo, 13 antebraço direito, 14 punho esquerdo, 15 punho direito, 16 mão esquerdo, 17 mão direita, 18 coxa esquerda, 19 coxa direita, 20 joelho esquerdo, 21 joelho direito, 22 perna esquerda, 23 perna direita, 24 tornozelo esquerdo, 25 tornozelo direito, 26 pé esquerdo, 27 pé direito.

\subsection{Bicicleta Tradicional - 'Transporte'}

Pode-se observar que a bicicleta tradicional 'transporte', foi bem aceita pela maioria dos participantes (quadro 1), já que cerca de $90 \%$ destes não sentiram nenhum desconforto em $95 \%$ das partes do corpo. 


\section{$16^{\circ}$ \\ ERGODESIGN USIHC CINAHPA}

$16^{\circ}$ Ergodesign - Congresso Internacional de Ergonomia e Usabilidade de Interfaces Humano Tecnológica: Produto, Informações Ambientes Construídos e Transporte

$16^{\circ}$ USIHC - Congresso Internacional de Ergonomia e Usabilidade de Interfaces Humano Computador

CINAHPA | 2017 - Congresso Internacional de Ambientes Hipermídia para Aprendizagem.

\begin{tabular}{|c|c|c|c|c|c|}
\hline $\begin{array}{c}\text { Níveis de } \\
\text { desconforto/dor } \\
\text { Partes do corpo }\end{array}$ & $\begin{array}{c}\text { (1) } \\
\text { Nenhum }\end{array}$ & $\begin{array}{c}(2) \\
\text { Algum }\end{array}$ & $\begin{array}{c}\text { (3) } \\
\text { Moderado }\end{array}$ & $\begin{array}{c}(4) \\
\text { Bastante }\end{array}$ & $\begin{array}{c}(5) \\
\text { Intolerável }\end{array}$ \\
\hline 00pescoço & $20(100 \%)$ & & & & \\
\hline 01 cervical & $20(100 \%)$ & & & & \\
\hline 02dorsal & $20(100 \%)$ & & & & \\
\hline 03 cintura & $20(100 \%)$ & & & & \\
\hline 04 lombar & $18(90 \%)$ & $01(5 \%)$ & $01(5 \%)$ & & \\
\hline 05região púbica & $09(45 \%)$ & $01(5 \%)$ & $03(15 \%)$ & $04(20 \%)$ & $03(15 \%)$ \\
\hline 06ombroesquerdo & $19(95 \%)$ & $01(5 \%)$ & & & \\
\hline 07ombro direito & $19(95 \%)$ & $01(5 \%)$ & & & \\
\hline 08braço esquerdo & $19(95 \%)$ & $01(5 \%)$ & & & \\
\hline 09braço direito & $19(95 \%)$ & $01(5 \%)$ & & & \\
\hline $\begin{array}{c}\begin{array}{c}\text { 10cotovelo } \\
\text { esquerdo }\end{array} \\
\end{array}$ & $20(100 \%)$ & & & & \\
\hline 11 cotovelo direito & $20(100 \%)$ & & & & \\
\hline $\begin{array}{c}\begin{array}{c}\text { 12antebraço } \\
\text { esquerdo }\end{array} \\
\end{array}$ & $20(100 \%)$ & & & & \\
\hline $\begin{array}{c}\text { 13antebraço } \\
\text { direito }\end{array}$ & $20(100 \%)$ & & & & \\
\hline 14punhoesquerdo & $20(100 \%)$ & & & & \\
\hline 15punho direito & $20(100 \%)$ & & & & \\
\hline 16mão esquerda & $20(100 \%)$ & & & & \\
\hline 17mão direito & $20(100 \%)$ & & & & \\
\hline 18 coxa esquerda & $18(90 \%)$ & & $02(10 \%)$ & & \\
\hline 19coxa direita & $18(90 \%)$ & & $02(10 \%)$ & & \\
\hline $\begin{array}{l}\text { 20joelho } \\
\text { esquerdo }\end{array}$ & $19(95 \%)$ & $01(5 \%)$ & & & \\
\hline 21 joelho direito & $19(95 \%)$ & $01(5 \%)$ & & & \\
\hline 22perna esquerda & $20(100 \%)$ & & & & \\
\hline \begin{tabular}{|l|} 
23perna direita \\
\end{tabular} & $20(100 \%)$ & & & & \\
\hline $\begin{array}{c}\text { 24tornozelo } \\
\text { esquerdo }\end{array}$ & $20(100 \%)$ & & & & \\
\hline $\begin{array}{l}\text { 25tornozelo } \\
\text { direito }\end{array}$ & $20(100 \%)$ & & & & \\
\hline 26pé esquerdo & $20(100 \%)$ & & & & \\
\hline 27pé direito & $20(100 \%)$ & & & & \\
\hline
\end{tabular}

Quadro 1 - Bicicleta tradicional - 'transporte': Níveis de Desconforto Geral Feminino e Masculino

Fonte: MariñoPequini (2005)

\subsection{Bicicleta aerodinâmica - 'Mountain Bike'}

Na bicicleta aerodinâmica (quadro 2), nota-se que os dados se apresentam heterogêneos, o que conclui a divergência de opinião em relação ao nível de desconforto entre homens e mulheres.

Enfim, a autora concluiu a partir dos resultados apresentados nos quadros 1 e 2 que a bicicleta tradicional - 'transporte' é mais confortável, já que cerca de $90 \%$ destes não sentiram nenhum desconforto/dor em $95 \%$ das partes do corpo, enquanto que a bicicleta aerodinâmica - 'mountain bike' foi bastante desconfortável, pois o nível de desconforto/dor apresentou-se mais intenso na região púbica, isto é, $85 \%$ deles consideraram "moderado", "bastante" e "intolerável"; destes, $60 \%$ sentiram intolerável desconforto. Além disso, uma boa parte dos ciclistas sentiu alguns incômodos nos membros inferiores do corpo, como é o caso dos pés, em que $60 \%$ e $45 \%$ sentiram "algum", "bastante" e até mesmo "intolerável" desconforto/dor no pé direito e no pé esquerdo, respectivamente.

\begin{tabular}{|c|c|c|c|c|c|}
\hline $\begin{array}{c}\text { Níveis de } \\
\text { desconforto/dor } \\
\text { Partes do corpo }\end{array}$ & $\begin{array}{c}(1) \\
\text { Nenhum }\end{array}$ & $\begin{array}{c}(2) \\
\text { Algum }\end{array}$ & $\begin{array}{c}(3) \\
\text { Moderado }\end{array}$ & \begin{tabular}{c||}
$(4)$ \\
Bastante
\end{tabular} & $\begin{array}{c}(5) \\
\text { Intolerável }\end{array}$ \\
\hline 00pescoço & $16(80 \%)$ & $\begin{array}{c}03 \\
(15 \%)\end{array}$ & & $01(5 \%)$ & \\
\hline 01cervical & $13(65 \%)$ & $01(5 \%)$ & $04(20 \%)$ & $02(10 \%)$ & \\
\hline 02dorsal & $18(90 \%)$ & $01(5 \%)$ & & & $01(5 \%)$ \\
\hline 03cintura & $18(90 \%)$ & $01(5 \%)$ & & $01(5 \%)$ & \\
\hline 04 lombar & $17(85 \%)$ & $01(5 \%)$ & $01(5 \%)$ & & $01(5 \%)$ \\
\hline 05região púbica & $08(40 \%)$ & & $02(10 \%)$ & $07(35 \%)$ & $03(15 \%)$ \\
\hline $\begin{array}{l}\text { 06ombro } \\
\text { esquerdo }\end{array}$ & $14(70 \%)$ & & $02(10 \%)$ & $03(15 \%)$ & $01(5 \%)$ \\
\hline 07ombro direito & $14(70 \%)$ & & $02(10 \%)$ & $03(15 \%)$ & $01(5 \%)$ \\
\hline 08braço esquerdo & $11(55 \%)$ & $\begin{array}{c}02 \\
(10 \%) \\
\end{array}$ & $02(10 \%)$ & $03(15 \%)$ & $02(10 \%)$ \\
\hline 09braço direito & $11(55 \%)$ & $\begin{array}{c}02 \\
(10 \%)\end{array}$ & $02(10 \%)$ & $03(15 \%)$ & $02(10 \%)$ \\
\hline $\begin{array}{c}\text { 10cotovelo } \\
\text { esquerdo }\end{array}$ & $14(70 \%)$ & $01(5 \%)$ & $02(10 \%)$ & $03(15 \%)$ & \\
\hline 11 cotovelo direito & $14(70 \%)$ & $01(5 \%)$ & $02(10 \%)$ & $03(15 \%)$ & \\
\hline $\begin{array}{c}\text { 12antebraço } \\
\text { esquerdo }\end{array}$ & $09(45 \%)$ & $\begin{array}{c}02 \\
(10 \%) \\
\end{array}$ & $03(15 \%)$ & $05(25 \%)$ & $01(5 \%)$ \\
\hline $\begin{array}{c}13 \text { antebraço } \\
\text { direito }\end{array}$ & $09(45 \%)$ & $\begin{array}{c}02 \\
(10 \%) \\
\end{array}$ & $03(15 \%)$ & $05(25 \%)$ & $01(5 \%)$ \\
\hline 14punhoesquerdo & $12(60 \%)$ & $01(5 \%)$ & $04(20 \%)$ & $03(15 \%)$ & \\
\hline 15punho direito & $12(60 \%)$ & $01(5 \%)$ & $04(20 \%)$ & $03(15 \%)$ & \\
\hline 16mão esquerda & $11(55 \%)$ & $01(5 \%)$ & $02(10 \%)$ & $05(25 \%)$ & $01(5 \%)$ \\
\hline 17mão direito & $11(55 \%)$ & $01(5 \%)$ & $02(10 \%)$ & $05(25 \%)$ & $01(5 \%)$ \\
\hline 18 coxa esquerda & $17(85 \%)$ & & $01(5 \%)$ & $02(10 \%)$ & \\
\hline 19coxa direita & $17(85 \%)$ & & $01(5 \%)$ & $02(10 \%)$ & \\
\hline $\begin{array}{l}\text { 20joelho } \\
\text { esquerdo }\end{array}$ & $19(95 \%)$ & $01(5 \%)$ & & & \\
\hline 21 joelho direito & $19(95 \%)$ & $01(5 \%)$ & & & \\
\hline 22perna esquerda & $19(95 \%)$ & & & $01(5 \%)$ & \\
\hline 23perna direita & $19(95 \%)$ & & & $01(5 \%)$ & \\
\hline $\begin{array}{c}\text { 24tornozelo } \\
\text { esquerdo }\end{array}$ & $\begin{array}{c}20 \\
(100 \%) \\
\end{array}$ & & & & \\
\hline $\begin{array}{c}25 \text { tornozelo } \\
\text { direito }\end{array}$ & $\begin{array}{c}20 \\
(100 \%) \\
\end{array}$ & & & & \\
\hline 26pé esquerdo & $19(95 \%)$ & & $01(5 \%)$ & & \\
\hline 27pé direito & $19(95 \%)$ & & $01(5 \%)$ & & \\
\hline
\end{tabular}

Quadro 2 - Bicicleta aerodinâmica - 'mountain bike':

Níveis de Desconforto Geral Feminino e Masculino Fonte: MariñoPequini (2005)
Realização:

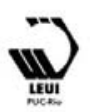




\section{$16^{\circ}$ \\ ERGODESIGN USIHC CINAHPA}

\section{Os três níveis de processamento cerebral}

Os estudos de Norman (2008) sobre design emocional sugerem que os atributos humanos de cognição resultam em três diferentes níveis de estrutura do cérebro: a camada automática, préprogramada, chamada de nível visceral. A parte cujo os processos cerebrais controlam o comportamento cotidiano, conhecida como nível comportamental. E a parte completativa do cérebro ou nível reflexivo.

Na prática, segundo o autor, o nível visceral é de rotinas fixas e anterior ao pensamento. Diz respeito ao impacto inicial de um produto, sua aparência, toque e sensação. Nele se formam as primeiras impressões. O nível comportamental é comum em operações rotineiras, e também não é um nível consciente. Diz respeito ao uso, e sobre a experiência com o produto. No nível reflexivo a consciência e os mais altos níveis de sentimentos, emoções e cognição residem.

Para constatar a importância da aparência na seleção de produtos pelos usuários, elaboramos uma pesquisa que deverá ser avaliada por usuários, que vivem diretamente e diariamente em um posto de trabalho e constituem importantes fundamentos para o projeto ergonômico.

\section{Proposta metodológica da pesquisa}

Para aplicação da pesquisa foram analisados e definidos por Mariño e Silveira (2016) os parâmetros necessários à seleção de bicicletas, pelos usuários.

\begin{tabular}{|l|c|c|}
\hline \multicolumn{1}{|c|}{$\begin{array}{c}\text { Parâmetros de avaliação } \\
\text { emocional }\end{array}$} & $\begin{array}{c}\text { Bicicleta de } \\
\text { transporte }\end{array}$ & Mountain Bike \\
\hline Segura & Sim & Sim \\
\hline Veloz & Não & Sim \\
\hline Resistente & Sim & Sim \\
\hline $\begin{array}{l}\text { Confortável (postura e ajuste } \\
\text { do selim) }\end{array}$ & Sim & Não \\
\hline
\end{tabular}

Quadro 3-Quadro comparativo dos parâmetros de avaliação emocional da bicicleta de transporte e mountain bike

Fonte: Mariño e Silveira (2016) $16^{\circ}$ Ergodesign - Congresso Internacional de Ergonomia e Usabilidade de Interfaces Humano Tecnológica: Produto, Informações Ambientes Construídos e Transporte

$16^{\circ}$ USIHC - Congresso Internacional de Ergonomia e Usabilidade de Interfaces Humano Computador

CINAHPA | 2017 - Congresso Internacional de Ambientes Hipermídia para Aprendizagem.

MariñoPequini (2005) a partir das notas de Palmer (1983), levantou que o produto deve atender determinados requisitos para atingir os objetivos esperados. A partir de Lobach (2001), MariñoPequini (2005) destaca que os aspectos essenciais de relações dos indivíduos com os objetos são as suas funções, que possibilitam a satisfação de necessidades. Portanto, as bicicletas selecionadas para a pesquisa de MariñoPequini também serão avaliadas quanto aos níveis emocionais, caracterizados de acordo com os estudos de Norman (2004), Lobach (2001, apud MARIÑOPEQUINI, 2005) e Palmer (1983, apud MARIÑOPEQUINI, 2005), conforme quadro 4 (MARIÑO e SILVEIRA, 2016).

\begin{tabular}{|c|c|c|}
\hline Níveis & $\begin{array}{l}\text { Bicicleta de } \\
\text { transporte }\end{array}$ & $\begin{array}{l}\text { Mountain } \\
\text { Bike }\end{array}$ \\
\hline $\begin{array}{l}\text { Comportamental (usabilidade - } \\
\text { postura e ajuste do selim) }\end{array}$ & Atende & Não atende \\
\hline Visceral (aparência) & Não Atende & Atende \\
\hline Reflexivo & Pode Atender & Pode Atender \\
\hline Funções & $\begin{array}{l}\text { Bicicleta de } \\
\text { transporte }\end{array}$ & $\begin{array}{l}\text { Mountain } \\
\text { Bike }\end{array}$ \\
\hline $\begin{array}{l}\text { Ergonômica (postura e ajuste do } \\
\text { selim) }\end{array}$ & Atende & Não atende \\
\hline Prática (função) & Atende & Atende \\
\hline Simbólica (aparência) & Não Atende & Atende \\
\hline Requisitos & $\begin{array}{l}\text { Bicicleta de } \\
\text { transporte }\end{array}$ & $\begin{array}{l}\text { Mountain } \\
\text { Bike }\end{array}$ \\
\hline $\begin{array}{l}\text { Ergonômico (postura e ajuste do } \\
\text { selim) }\end{array}$ & Atende & Não atende \\
\hline $\begin{array}{l}\text { Tecnológico (resistência e } \\
\text { materiais industriais) }\end{array}$ & Atende & Atende \\
\hline Estético (aparência) & Não Atende & Atende \\
\hline
\end{tabular}

Quadro 4 - Avaliação dos aspectos atendidos pelas bicicletas de transporte e mountain bike Fonte: Mariño e Silveira (2016)

Com base nos estudos conclusivos apresentados nos quadros 3 e 4 foi elaborada a matriz de avaliação emocional das bicicletas (quadro 5). Cabe salientar que a matriz gerada também levou em consideração o estudo da metodologia Kansei (LEE; MARGHAN; HEEMAN, 2017) que tem por prática a compreensão das emoções pessoas para projetação de novos produtos. 


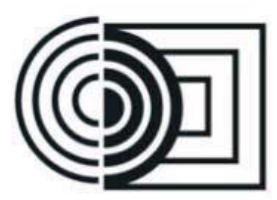

$16^{\circ}$ Ergodesign - Congresso Internacional de Ergonomia e Usabilidade de Interfaces Humano Tecnológica: Produto, Informações Ambientes Construídos e Transporte

$16^{\circ}$ USIHC - Congresso Internacional de Ergonomia e Usabilidade de Interfaces Humano Computador

CINAHPA | 2017 - Congresso Internacional de Ambientes Hipermídia para Aprendizagem.

\begin{tabular}{|l|l|l|l|l|l|l|l|l|}
\hline \multirow{2}{*}{ Parâmetros } & \multicolumn{7}{|c|}{ Nível emocional } & \multirow{2}{*}{ Parâmetros } \\
\cline { 2 - 8 } & $\mathbf{7}$ & $\mathbf{6}$ & $\mathbf{5}$ & $\mathbf{4}$ & $\mathbf{3}$ & $\mathbf{2}$ & $\mathbf{1}$ & Não- segura \\
\hline Segura & & & & & & & & Não-veloz \\
\hline Veloz & & & & & & & & \\
\hline Elegante & & & & & & & & $\begin{array}{l}\text { Não- } \\
\text { elegante }\end{array}$ \\
\hline Resistente & & & & & & & & $\begin{array}{l}\text { Não- } \\
\text { resistente }\end{array}$ \\
\hline Bela & & & & & & & & Não-bela \\
\hline Confortável & & & & & & & & $\begin{array}{l}\text { Não } \\
\text { confortável }\end{array}$ \\
\hline
\end{tabular}

Quadro 5 - Matriz de avaliação emocional das bicicletas Fonte: Silveira e Mariño (2016)

Para a coleta final de dados da pesquisa tornar-se-á necessário a compreensão das partes das bicicletas analisadas (figuras 5 e 6 ) bem como a relação das mesmas com os parâmetros de avaliação emocional, para tanto foi desenvolvida a matriz apresentada no quadro 6 , que deverá ser aplicada com os usuários.

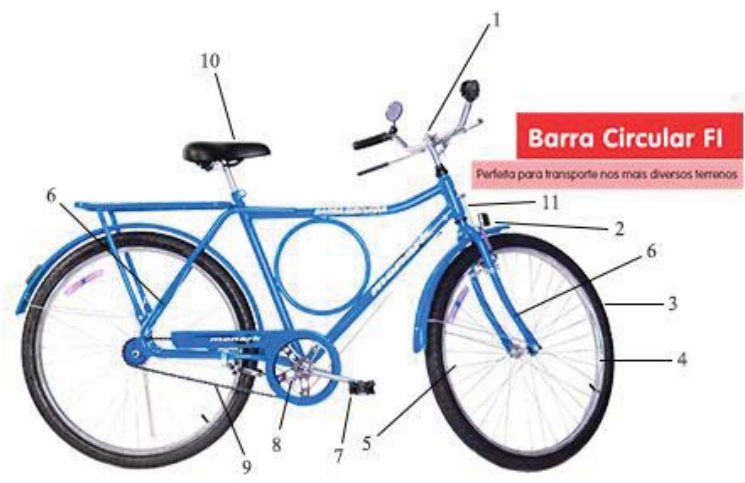

Figura 5 - Partes da Bicicleta tradicional 'transporte' Fonte: http//:monark.com.br/produtos

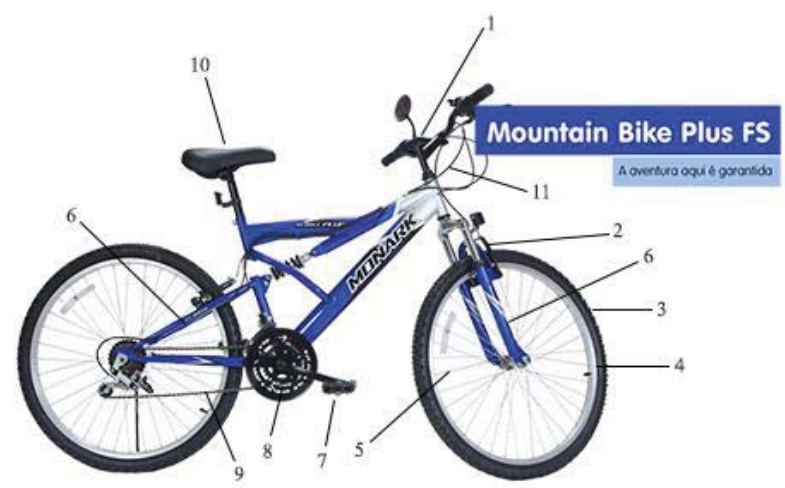

Figura 6 - Partes da Bicicleta aerodinâmica 'mountain bike'

Fonte: http//:monark.com.br/produtos
Legenda: parte das bicicletas

$\begin{array}{llllll}\text { 1. } & \text { Guidão } & \text { 5. } & \text { Raios } & \text { 9. } & \text { Corrente } \\ \text { 2. } & \text { Freio } & \text { 6. } & \text { Garfos } & \text { 10. } & \text { Selim } \\ \text { 3. } & \text { Pneus } & \text { 7. } & \text { Pedal } & \text { 11. } & \text { Cabo do Freio } \\ \text { 4. } & \text { Aro } & \text { 8. } & \text { Coroa } & & \end{array}$

\begin{tabular}{|l|l|l|l|l|l|l|}
\hline & \multicolumn{6}{|c|}{ Parâmetros } \\
\hline $\begin{array}{l}\text { Partes da } \\
\text { bicicleta }\end{array}$ & Segura & Veloz & Elegante & Resistente & Bela & Confortável \\
\hline Guidão & & & & & & \\
\hline Freio & & & & & & \\
\hline Aro & & & & & & \\
\hline Raios & & & & & & \\
\hline Garfos & & & & & & \\
\hline Pedal & & & & & & \\
\hline Coroas & & & & & & \\
\hline Corrente & & & & & & \\
\hline Selim & & & & & & \\
\hline $\begin{array}{l}\text { Cabos dos } \\
\text { freios }\end{array}$ & & & & & & \\
\hline Quadro & & & & & & \\
\hline Pneus & & & & & & \\
\hline
\end{tabular}

Quadro 6 - Matriz de correlação dos parâmetros com as partes das bicicletas

Fonte: Silveira e Mariño (2016)

Como pressuposto das etapas da coleta de dados, a pesquisa será dividida em duas etapas.

$1^{\circ}$ - definição da amostra de usuários para aplicação das matrizes, que deverá levar em consideração 2 grupos: grupo por idade e por prática/uso de bicicletas. No grupo por idade deverão existir 2 subgrupos com usuários nas faixas etárias de 20 a 35 anos e de 36 em diante; e no grupo por prática/uso terão 2 subgrupos, 1 de usuários praticantes de atividades físicas com uso de bicicleta e outro de usuários não praticantes. Tal divisão da amostra pretende avaliar a influência da idade e da prática de atividade física nos parâmetros;

$2^{\circ}$ - serão apresentadas as bicicletas aos usuários baseado na análise visual das mesmas os usuários deverão preencher a matriz de avaliação emocional (quadro 5) e, em seguida, a matriz de correlação dos parâmetros com as partes das bicicletas (quadro 6).

Considerando os requisitos ergonômicos e tecnológicos dos objetos além da importância da aparência na hora de escolher produtos, faz-se necessária a reflexão que comprova a evidência e relevância das emoções no controle do
Realização:

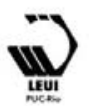




\section{$16^{\circ}$ \\ ERGODESIGN USIHC CINAHPA}

comportamento humano gerada por meio da cognição. Para tanto, a abordagem da pesquisa propõe compreender a influência dos aspectos viscerais comportamentais e reflexivos no design dos objetos.

Salienta-se que a pesquisa está em fase de aplicação das matrizes para coleta de dados, bem como ressalta-se o desafio da pesquisa em termos de aplicação de conceitos ainda pouco explorados, contudo faz-se necessário tal desbravamento para se galgar novos patamares ao design. Esta pesquisa abre possibilidades para se pensar e observar a utilização das referências emocionais, no design de produtos.

\section{Bibliografia}

COSTA, Filipe Campelo Xavier e TONETTO, Leandto Miletto. Design Emocional: conceitos, abordagens e perspectivas de pesquisa. Strategic Design Research Journal, 4(3): 132-140. Setembro-dezembro, 2011.

DAMÁZIO, Vera. Design, memória, emoção: uma investigação para o projeto de produtos memoráveis. Barbacena: Eduemg, 2013. 19 p.

DESMET, P. 2009. Special Issue Editorial: Design \& Emotion. International Journal of Design, 3(2):1-6.

FONTOURA, Antônio M. e Cláudia R. Hasegawa, ZACAR. Quando o design mexe com a gente. In: abc Design. Ed n. 25. Curitiba, 2008. ISSN 1676-5656.

LEE, Erika Yamamoto; MARGHAN, Viviane i Gaspar Ribas El e HEEMAN, Adriano. Fundamentos da engenharia kansei: Uma revisão bibliográfica e sua relação entre o design de superfície e o interior de aeronave. Revista Ergodesign \& HCI, [S.1.], v. 4, n. Especial, p. 33-39, jan. 2017. ISSN 2317-8876.

LÖBACH, Bernd. Design Industrial: bases para a configuração dos produtos industriais. São Paulo: Edgar Blücher, 2001

MARGHANI, V. G. R.; GABARDOA, A. C.; SILVA, A. S. de A.; SILVA, F. C. da; SALATA, N. S. Kansei Engineering: metodologia orientada ao consumidor para suporte a decisão de projeto. In: $8^{\circ}$ Congresso Brasileiro de Gestão de Desenvolvimento de Produtos. 2011. Porta Alegre. Setembro, 2011. $16^{\circ}$ Ergodesign - Congresso Internacional de Ergonomia e Usabilidade de Interfaces Humano Tecnológica: Produto, Informações Ambientes Construídos e Transporte

$16^{\circ}$ USIHC - Congresso Internacional de Ergonomia e Usabilidade de Interfaces Humano Computador

CINAHPA | 2017 - Congresso Internacional de Ambientes Hipermídia para Aprendizagem.

MARINO, Suzi; SILVEIRA, Carina. Escalas de avaliação de percepção de parâmetros em relação a produtos: Requisitos, Funções e Níveis cerebrais. Salvador: UFBA: PPGAV, 2016. 5 p. Disponível em: <www.posdesign.com.br>. Acesso em: 01 fev. 2017.

MARIÑOPEQUINI, Suzi. A evolução tecnológica da bicicleta e suas implicações ergonômicas para a máquina humana: problemas na coluna vertebral $\mathrm{x}$ bicicletas dos tipos Speed e Mountain bike. 2000. $200 \mathrm{f}$. Dissertação (Mestrado) - Curso de Arquitetura e Urbanismo, Arquitetura, Universidade de São Paulo, São Paulo, 2000.

MARIÑOPEQUINI, Suzi. Ergonomia aplicada ao design de produtos: Um estudo de caso sobre o design de bicicletas. 2005. $630 \mathrm{f}$. Tese (Doutorado) - Curso de Arquitetura e Urbanismo, Arquitetura, Universidade de São Paulo, São Paulo, 2005.

MONT’ALVÃO, Claudia; DAMAZIO, Vera. (Org.) Design, ergonomia e emoção. Rio de Janeiro: Mauad X, 2008. p. 19-30.

NORMAN, Donald A. Design Emocional: Por que adoramos (ou detestamos) os objetos do dia-a-dia. Rio de Janeiro: Rocco, 2008. 278 p. Tradução de: Ana Deiró.

SILVEIRA, Carina Santos; MARIÑO, Suzi Maria. O prazer do vestir - Moda, ergonomia e referências culturais. In: CONGRESSO BRASILEIRO DE ERGONOMIA, 18., 2016, Salvador. 18-congressoergonomia-27272. Belo Horizonte, 2016.

TONETTO, Leandro Miletto; COSTA, Filipe Campelo Xavier da. Design Emocional: conceitos, abordagens e perspectivas de pesquisa. Strategic Design

Research Journal, Chicago, v. 3, n. 4, p.1-9, set. 2011. Disponível em: <file://C:/Users/titto/Downloads/449214861-1-SM (1).pdf $>$. Acesso em: 15 out. 2016.

VIANA, Ilca Oliveira. Metodologia de Trabalho Científico: Um enfoque didático da produção científica. São Paulo: Epu, 2001. 304 p.
Realização:
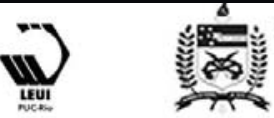